\title{
Correction to: Gastroesophageal reflux disease: from heartburn to Barrett esophagus, and beyond
}

\author{
Marco G. Patti ${ }^{1} \cdot$ Francisco Schlottmann $^{1}$
}

Published online: 21 September 2018

(c) Italian Society of Surgery (SIC) 2018

Correction to: Updates in Surgery (2018) 70:307

\section{https://doi.org/10.1007/s13304-018-0587-4}

The author name Marco G. Patti was incorrectly published.

The correct name is given below:

Marco G. Patti.

The original article has been corrected.

The original article can be found online at https://doi.org/10.1007/ s13304-018-0587-4.

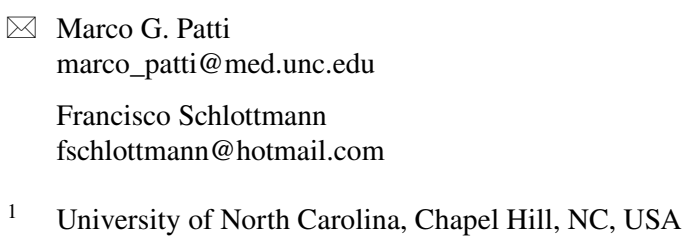

